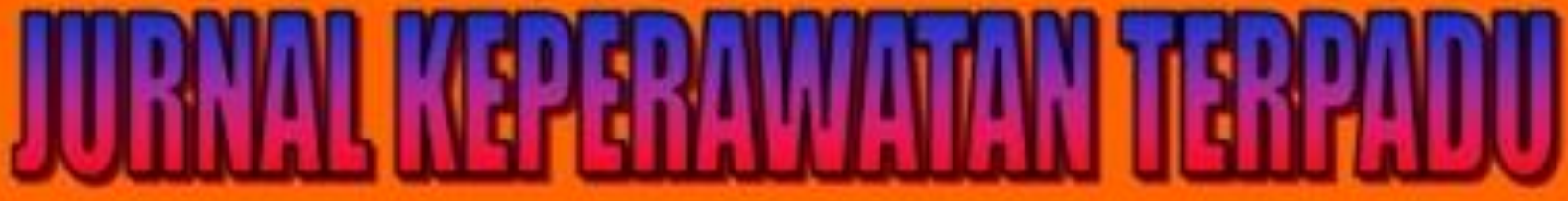

\section{Integrated Nursing Journal}

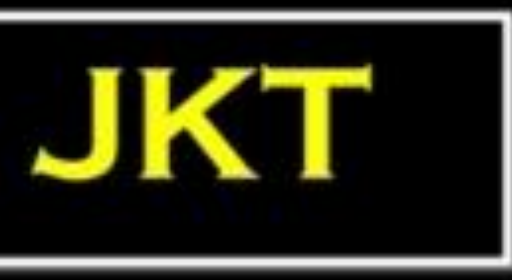

\section{p-ISSN: 2406-9698 (Print) e-ISSN: 2685-0710 (Online)}

\section{Vol. 2 No. 1 April 2020}

\section{KEMENTERIAN KESEHATAN RI}

\section{POLTEKKES MATARAM JURUSAN KEPERAWATAN}

Jalan Kesehatan V/10 Mataram NTB - http://jkt.poltekkes-mataram.ac.id 


\section{Vol. 2 No. 1 April 2020}

\section{Editorial Team}

\section{Editor-in-Chief}

Moh. Arip, Jurusan Keperawatan Poltekkes Kemenkes Mataram, Indonesia

\section{Editorial Board}

1. Mr. Frans Judea Samosir, Universitas Prima Indonesia, Indonesia

2. Baiq Kirana Kitna, Jurusan Keperawatan, Poltekkes Kemenkes Mataram, Indonesia

3. Irwan Budiana, Jurusan Keperawatan, Poltekkes Kemenkes Kupang, Indonesia

4. dr. Baskoro Tri Laksono, RS. Biomedika Mataram, Indonesia

5. Sitti Rusdianah, Jurusan Keperawatan, Poltekkes Kemenkes Mataram, Indonesia

6. Mira Utami Ningsih, Jurusan Keperawatan, Poltekkes Kemenkes Mataram, Indonesia

\section{Alamat Redaksi:}

Jurusan Keperawatan Mataram Poltekkes Kemenkes Mataram Kampus B

Jl. Kesehatan V No.10 Pajang Timur-Mataram NTB-Indonesia, 83127

Telepon: +62 370-621383

Fax: +62 370-631160

Email: jurnalkeperawatanterpadu2019@gmail.com

Laman: http://jkt.poltekkes-mataram.ac.id/index.php/home/index 


\section{Vol. 2, No. 1, April 2020}

\section{DAFTAR ISI}

Pengaruh Self Hypnosis Terhadap Respon Cemas Mahasiswa

Pada Ujian Tahap Akhir Program Di STIKes Buana Husada Ponorogo

Yudha Anggit Jiwantoro, Afifa Ika Kridawati, Danies Tunjung Pratiwi

Efektifitas Tepid Water Sponge Terhadap Penurunan Suhu Tubuh Pada Anak Dengan Masalah Keperawatan Hipertermia: Studi Kasus

Emy Mulyani, Nur Eni Lestari

Perilaku Pencegahan Penyakit Tidak Menular Pada Remaja Ambon

Hamdan Hariawan, Martini Tidore, Greeny Z. Rahakbau

Pengetahuan dan Sikap Perawat Berhubungan dengan Pelaksanaan Patient

Safety

Elisa Sulistia Fitri, Kusnanto, Herdina Maryanti

Efektivitas Art Therapy terhadap Pengetahuan dan Praktik Pemeliharaan Kesehatan Gigi pada Anak Usia Prasekolah

Linda Widyarani, Wiwi Kustio Priliana, Cecilya Kustanti

Konsep Diri Remaja Yang Mengalami Bullying

Puji Lestari, Liyanovitasari

Pengaruh Senam Tai Chi Terhadap Peningkatan Kualitas Tidur Lansia Di Balai Sosial Lanjut Usia Mandalika

Fathaillah Liestanto, Dina Fitriana

Hubungan Komunikasi Terapeutik Perawat Dengan Tingkat Kecemasan

Pasien Hemodialisa Di RSUD Dr Harjono Ponorogo

Ervan Nur Cholis, Rumpiati Rumpiati, Ike Sureni

Upaya Mengatasi Nyeri Post Op Sectio Cesaria Melalui Foot Massage Therapy Diruang Nifas RSUD Kota Mataram

Masadah, Cembun, Ridawati Sulaeman

Peningkatan Pemberdayaan Keluarga Melalui PINKESGA (Paket Informasi Keluarga) Kehamilan Dalam Mengambil Keputusan Merawat Ibu Hamil Mardiatun, Dewi Purnamawati, Ely Mawaddah
Page

$1-6$

Page

$7-14$

Page

$15-21$

Page

22-28

Page

29-39

Page

40-46

Page

$47-53$

Page

54-63

Page

$64-70$

Page

$70-78$ 


\title{
Pengaruh Foot Massage Therapy terhadap Skala Nyeri Ibu Post Op Sectio Cesaria di Ruang Nifas RSUD Kota Mataram
}

\author{
Masadah $^{1}$, Cembun $^{2}$, Ridawati Sulaeman ${ }^{3}$ \\ 1,2,3 Jurusan Keperawatan, Poltekkes Kemenkes Mataram, Indonesia
}

\begin{abstract}
Abstrak
Pasien yang menjalani persalinan dengan metode Sectio Cesarea biasanya merasakan ketidaknyamanan yaitu nyeri yang berasal dari insisi abdominal. salah satu teknik mengurangi nyeri secara non farmakologi adalah Foot massage therapy. Penelitian ini bertujuan untuk mengidentifikasi efek Foot massage therapy terhadap nyeri pasien post op sectio cesarea. Desain penelitian ini adalah Pre Eksperimental dengan rancangan Pretest-Posttest. Sampel adalah 42 ibu post section secarea di RSUD Kota Mataram yang dipilih dengan teknik Purposive sampling. Data tentang nyeri dikumpulkan dengan Numeric Rating Scale (NRS). Hasil penelitian menunjukan bahwa skala ratarata nyeri sebelum intervensi yaitu 6,55 sedangkan skala nyeri sesudah intervensi 4,86 . Uji wilcoxon menunjukan hasil $\rho=0,00<\alpha=0,05$. Persentase responden dengan nyeri berat setelah intervensi menjadi $0 \%$. Persentase responden dengan nyeri sedang juga menurun dari $84 \%$ pre intervensi menjadi $54 \%$ post intervensi. Dari hasil penelitian dapat disimpulkan bahwa ada pengaruh signifikan foot massage therapy terhadap perubahan nyeri pasien post op Sectio Cesarea. Perawat dapat mengaplikasikan foot massage therapy pada pasien post operasi Sectio Cesarea sebagai intervensi untuk mengurangi nyeri.
\end{abstract}

Kata Kunci: foot massage therapy; Nyeri; Sectio Caesarea

\section{The Effect of Foot Massage Therapy on Post Sectio Cesarea Pain Among Patients at Post Partum Ward RSUD Kota Mataram}

\begin{abstract}
in the Post Partum Ward RSUD Kota Mataram Patients who underwent Sectio Cesarea usually feel discomfort such as pain from the abdominal incision. One of the non-pharmacological techniques to reduce pain is foot massage therapy. This study aims to determine the effect of Foot massage therapy on changes in post Sectio Cesarean pain. The design of this study was Pre Experimental with PretestPosttest design. Sampel were 42 post sectio caesarea patients at post partum ward RSUD Kota Mataram selected using Purposivel sampling technique. Data of pain scale were collected using Numeric Rating Scale (NRS). Result shows that the average pain scale before intervention was 6.55 and after intervention was 4.86. Wilcoxon statistical analysis shows $\rho=0,00<\alpha=0,05$. The percentage of patients with severe pain after intervention was $0 \%$. The percentage of patients with mild pain was decrease from $84 \%$ pre intervention to $54 \%$ post intervention. It can be concluded that there was a significant effect of foot massage therapy on the pain scale among patients with post sectio cesarean. Nurses can apply this therapy as an intervention for reducing post section cesarean pain.
\end{abstract}

Keywords: Foot massage therapy; Pain; Sectio Cesarea 


\section{PENDAHULUAN}

Persalinan dengan Sectio Cesarea merupakan tindakan yang berisiko, dampak yang ditimbulkan antara lain berupa perdarahan, infeksi, emboli paru-paru, kegagalan ginjal akibat hipotensi yang lama. Pasien yang menjalani persalinan dengan metode Sectio Cesarea biasanya merasakan berbagai ketidaknyamanan. Ketidaknyamanan salah satunya nyeri yang berasal dari insisi abdominal (Reeder, 2011). Sectio Cesarea biasanya dilakukan atas indikasi yang terbatas pada panggul sempit dan placenta previa, namun pada waktu ini angka kejadian Sectio Cesarea cenderung meningkat antara lain karena disebabkan karena berkembangnya indikasi serta kemajuan tehnik operasi dan anastesi (Cunningham et al, 2010).

Nyeri dapat menimbulkan berbagai masalah pada ibu maupun bayi. Dampak nyeri terhadap ibu, yaitu Activity Daily Living (ADL) dan mobilisasi ibu menjadi terbatas karena adanya peningkatan intensitas nyeri apabila ibu bergerak. Pada hasil penelitian yang dilakukan oleh Purwanti (2014) disebutkan bahwa perdarahan pada luka post Sectio Cesarea karena tidak adanya mobilisasi dini mengakibatkan kontraksi uterus lemah sehingga terjadi pelebaran pembuluh darah yang dapat mengakibatkan perdarahan. Dampak nyeri terhadap bayi yaitu pemberian ASI, dan kurangnya perawatan bayi yang dilakukan oleh ibunya sehingga ASI sebagai makanan terbaik dan mempunyai banyak manfaat bagi bayi tidak dapat diberikan secara optimal (Indriati, 2010)

Menurut World Health Organisation (WHO), standar rata-rata Sectio Cesarea disebuah negara adalah sekitar 5-15\% per 1000 kelahiran, di Indonesia Tahun 2012 sebanyak (16\%). Angka kejadian Sectio Cesarea di Indonesia menurut data survey nasional pada tahun 2007 adalah 921.000 dari 4.039.000 jumlah persalinan secara keseluruhan (22,8\%). Berdasarkan data RISKESDAS persalinan Sectio Cesarae Tahun 2013 sebanyak (9,8\%), sedangkan di Nusa Tenggara Barat persalinan dengan Sectio Cesarea pada tahun 2012 sebanyak (9,7\%). Berdasarkan hasil studi pendahuluan yang dilakukan oleh peneliti jumlah persalinan dengan Sectio Cesarea di RSUD Kota Mataram pada tahun 2015 sebanyak 1.341 (54\%),pada tahun 2016 jumlah persalinan dengan Sectio Cesarea sebanyak $1.514(84,78 \%)$ dan pada tahun 2017 jumlah persalinan dengan Sectio Cesarea dari bulan januarioktober yaitu 1.561 dengan rata-rata perbulan sekitar 156.

Nyeri yang dirasakan pada Sectio Cesarea berasal dari luka yang terdapat dari perut, disebabkan ketika bagian tubuh terluka oleh sayatan akan mengeluarkan berbagai macam substansi intraseluler dilepaskan ke ruang ekstraseluler maka akan mengiritasi nosiseptor. Saraf ini akan merangsang dan bergerak sepanjang serabut saraf atau neurotransmisi yang akan menghasilkan substansi yang disebut dengan neurotransmitter seperti prostaglandin dan epineprin, yang membawa pesan nyeri dari medulla spinalis ditansmisikan ke otak dan dipersepsikan sebagai nyeri. Nyeri biasanya terjadi pada 12 sampai 36 jam setelah pembedahan, dan menurun pada hari ketiga (Judha, 2012). 
Proses asuhan Keperawatan pasca operasi sangat penting dilakukan sedini mungkin dan secara komprehensif untuk mengatasi terjadinya masalah keperawatan. Peran perawat dituntut untuk dapat mengatasi masalah keperawatan seperti nyeri yang dirasakan pada pasien post pembedahan, karena perawat selama 24 jam mengetahui kondisi pasien baik fisiologi maupun psikologi. Manajemen dalam mengatasi nyeri haruslah mencakup penanganan secara keseluruhan, tidak hanya farmakologis, melainkan juga non farmakologis yang dipandang lebih aman. Beberapa teori komplementer dapat meningkatkan kenyamanan pasien sebagai contoh terapi musik, relaksasi, teknik meditasi, pijat refleksi, obat herbal, hipnotis, terapi sentuh dan massage. Berdasarkan hasil peneltian yang dilakukan (Fitriani,2013) menunjukan bahwa teknik relaksasi nafas dalam dapat membantu dalam adaptasi nyeri pada pasien inpartu kala 1 , namun pada survey pendahuluan yang dilakukan di ruang Nifas RSUD Kota Mataram manajemen nyeri secara non farmakologis yang dilakukan hanya relaksasi nafas dalam dan tidak secara menyeluruh kepada semua pasien.

Foot massage therapy dapat memberikan efek untuk mengurangi rasa nyeri karena pijatan yang diberikan menghasilkan stimulus yang lebih cepat sampai ke otak dibandingkan dengan rasa sakit yang dirasakan sehingga menghasilkan serotonin dan dopamin (Gunnarsdottir \& Jonsdottir, 2007). Penelitian yang dilakukan oleh Luan Tsay (2009) terdapat pengaruh pemberian Foot massage therapy terhdap intensitas nyeri pasca operasi abdomen di Medikal Center Taipei, Taiwan dengan nilai $\rho$-value $<0,5$. Hal ini terbukti bahwa Foot massage therapy bermanfaat dalam penurunan intensitas nyeri akibat luka insisi post operasi abdomen atau laparatomi. Foot massage sangat dianjurkan sebagai salah satu intervensi keperawatan yang dapat meningkatkan peran perawat dalam manajemen nyeri, karena sebagai metode penghilang nyeri yang aman, tidak membutuhkan peralatan yang special, mudah dilakukan dan mempunyai efektivitas yang tinggi. Foot massage therapy dapat dilakukan pada pasien post operasi abdomen seperti SC (Chanif, 2012). Berdasarkan uraian di atas, peneliti tertarik untuk membahas tentang upaya mengatasi nyeri post Sectio Caesarea melalui Foot massage therapy di ruang Nifas RSUD Kota Mataram.

\section{METODE}

Penelitian ini menggunakan desain Pre Eksperimental dengan rancangan One Group pretestposttest. Sampel dalam penelitian ini adalah pasien yang telah dilakukan sectio cesarea di ruang Nifas RSUD Kota Mataram sebanyak 42 orang yang dipilih menggunakan tehnik purposive sampling. Variabel independen dalam penelitian ini adalah foot massage therapy, sedangkan variabel dependen adalah nyeri pada pasien post sectio cesarea. Setelah 24 jam post section secarea, dilakukan pengukuran nyeri menggunakan skala NRS sebagai pre test terhadap seluruh responden. Selanjutnya, seluruh responden diberikan intervensi Foot massage therapy selama total 20 menit, dengan masingmasing 10 menit pada setiap kaki. Pengukuran skala nyeri dilakukan kembali menggunakan skala NRS pada 1 jam setelah pemberian tindakan foot massasge therapy sebagai post test. 
Data skala nyeri responden pada sebelum dan sesudah diberikan intervensi foot massasge therapy ditabulasi dan dipersentasekan. Kemudian dilakukan uji wilcoxon signed rank test untuk menguji data skala nyeri sebelum dan sesudah intervensi untuk menilai pengaruh pemberian intervensi foot massasge therapy terhadap skala nyeri responden.

\section{HASIL PENELITIAN}

Dalam penelitian ini, nyeri responden dikategorikan menjadi empat, yaitu tidak nyeri (0), nyeri ringan (1-4), nyeri sedang (5-7), dan nyeri berat (8-10). Parameter nyeri sebelum diberikan intervesi Foot massage therapy dapat dilihat pada tabel 1.

Tabel 1. Rata-Rata Nyeri Ibu Post Sectio Cesarea Sebelum Foot massage therapy di Ruang Nifas RSUD Kota Mataram

\begin{tabular}{ccccc}
\hline Parameter & Rata-Rata & $\begin{array}{c}\text { Standar } \\
\text { Deviasi }\end{array}$ & Nilai Minimum & Nilai Maksimum \\
\hline Nyeri Sebelum Intervensi & 6,55 & 8,03 & 5 & 8 \\
\hline
\end{tabular}

Parameter nyeri sesudah diberikan intervesi Foot massage therapy dapat dilihat pada tabel 2.

Tabel 2. Rata-Rata Nyeri Ibu Post Sectio Cesarea Sesudah Foot massage therapy di Ruang Nifas RSUD Kota Mataram

\begin{tabular}{ccccc}
\hline Parameter & Rata-Rata & Standar Deviasi & Nilai Minimum & Nilai Maksimum \\
\hline $\begin{array}{c}\text { Nyeri Sesudah } \\
\text { Intervensi }\end{array}$ & 4,86 & 8,99 & 4 & 8 \\
\hline
\end{tabular}

Distribusi Nyeri Ibu Post Sectio Cesarea Sebelum Foot massage therapy yaitu responden terbanyak adalah responden yang termasuk dalam kategori nyeri sedang yaitu 35 orang (83\%), kategori nyeri berat sebanyak 7 orang (17\%) dan yang terendah adalah responden yang termasuk dalam kategori tidak nyeri yaitu $0(0 \%)$ serta nyeri ringan yaitu $0(0 \%)$. Distribusi nyeri Ibu post sectio cesarea Sesudah foot massage therapy yaitu 22 orang (52\%) nyeri sedang yaitu, nyeri ringan 20 responden (48\%) dan 0 reponden dengan nyeri berat dan tidak nyeri $(0 \%)$. 
Tabel 3. Hasil Uji Statistik Foot massage therapy Terhadap Nyeri Post Op Sectio Cesarea di Ruang Nifas RSUD Kota Mataram

\begin{tabular}{cccccc}
\hline \multirow{2}{*}{ No } & \multirow{2}{*}{ Kategori } & \multicolumn{2}{c}{ Pre-test } & \multicolumn{3}{c}{ Post-test } \\
\cline { 2 - 6 } & & $\mathrm{n}$ & $\%$ & $\mathrm{~N}$ & $\%$ \\
\hline 1 & Tidak Nyeri & 0 & $0 \%$ & 0 & $0 \%$ \\
\hline 2 & Nyeri Ringan & 0 & $0 \%$ & 20 & $48 \%$ \\
\hline 3 & Nyeri Sedang & 35 & $83 \%$ & 22 & $52 \%$ \\
\hline 4 & Nyeri Berat & 7 & $17 \%$ & 0 & $0 \%$ \\
\hline & Z & & $-424^{\mathrm{a}}$ & \\
\hline & Asymp.Sig (2-tailed) & & 0,00 & \\
\hline
\end{tabular}

Tabel 3 menunjukkan hasil uji wilcoxon untuk pengaruh Foot massage therapy terhadap perubahan nyeri pasien post op Sectio Cesarea diperoleh $\rho=0,00<\alpha=0,05$. Hal ini berarti ada pengaruh Foot massage therapy terhadap nyeri post op Sectio Cesarea di ruang Nifas RSUD Kota Mataram..

\section{PEMBAHASAN}

Berdasarkan hasil wawancara yang dilakukan menyatakan bahwa, responden yang mengalami nyeri berat disebabkan oleh stress akibat tindakan pembedahan Sectio Cesarea yang disertai dengan Histerektomi (Pengangkatan Rahim) . Hal ini sesuai dengan data hasil penelitian, terdapat 2 responden yang memiliki kategori nyeri berat. Dari hasil wawancara, responden merasa stress dan tidak tenang karena dilakukannya histerektomi akibat indikasi penyakit yang dideritanya (mioma uteri) serta merasa sedih karena dirasa belum mampu memberikan keturunan yang cukup untuk suaminya.

Berdasarkan hasil penelitian pada 42 responden pasien Post Sectio Cesarea, diperoleh nyeri terbanyak setelah intervensi Foot massage therapy adalah 22 orang dengan kategori sedang (52\%), kemudian 20 orang (48\%) dengan kategori ringan dan terendah adalah kategori tidak nyeri dan nyeri berat $(0 \%)$. Penurunan nyeri pada responden kemungkinan disebabkan oleh faktor pengalihan, yaitu ketika pasien mengalihkan perhatiannya dari nyeri ke hal-hal yang membuatnya senang dan bahagia maka pasien dapat melupakan nyeri yang sedang dialaminya (Patasik, 2013)

Foot massage therapy adalah suatu teknik yang dapat meningkatkan pergerakan beberapa struktur dari kedua otot dan jaringan subkutan, dengan menerapkan kekuatan mekanik ke jaringan. Pergerakan ini dapat meningkatkan aliran getah bening dan aliran balik vena, mengurangi pembengkakan dan memobilisasi serat otot, tendon dengan kulit. Dengan demikian, massage therapy dapat digunakan untuk meningkatkan relaksasi otot untuk mengurangi rasa sakit dan mempercepat pemulihan pasien setelah operasi (Anderson \& Cutshall, 2007). Foot massage dapat memberikan efek untuk mengurangi rasa nyeri karena pijatan yang diberikan menghasilkan stimulus yang lebih cepat sampai ke otak dibandingkan dengan rasa sakit yang dirasakan, sehingga meningkatan sekresi 
serotonin dan dopamin.Sedangkan efek pijatan merangsang pengeluaran endorfin, sehingga membuat tubuh terasa rileks karena aktifitas saraf simpatis menurun (Field, Hernandez-Reif, Diego, \&Fraser, 2007; Gunnarsdottir \& Jonsdottir,2007).

Dalam penelitian ini terdapat perbedaan penurunan nyeri pada tiap responden. Perbedaan penurunan yang terjadi pada setiap responden berbeda-beda. Hal ini disebabkan karena individu mempunyai sifat yang multidimensi, respon individu dalam mengatasi masalah yang terjadi berbedabeda. Tampak pada penelitian ini dengan perlakuan yang sama yaitu Foot massage therapy yang diberikan 24 jam post Sectio Cesarea selama 20 menit, ternyata penurunan nyeri setiap responden berbeda-beda. Perbedaan penurunan nyeri pada tiap responden dalam penelitian ini dilaporkan bahwa pada saat dilakukan Foot massage therapy ada dua sensasi yang berbeda yaitu merasakan sesuatu yang rileks, nyaman, enak, dan santai ketika otot-otot tubuh yang terutama bagian bawah yang sebelumnya kaku dipijat. Namun ada beberapa responden yang melaporkan kurang bisa merasakan sensasi dari Foot massage therapy karena mereka kurang bisa berkonsentrasi dan merasa kurang nyaman dengan tindakan yang dilakukan.

Hasil uji statistik menunjukkan $\rho=0,000(\alpha<0,05)$ artinya $\mathrm{H}_{0}$ ditolak dan $\mathrm{H}_{1}$ diterima, sehingga dapat disimpulkan bahwa ada pengaruh yang signifikan Foot massage therapy terhadap nyeri pasien post op Sectio Cesarea di Ruang Nifas RSUD Kota Mataram. Hal ini sejalan dengan penelitian dari (Nila, Krisna, 2016) yang dilakukan selama 2 minggu di Ruang Inap Bedah RSUP DR.M. Djamil Padang pada 12 responden. Hasil penelitian menunjukan bahwa rata-rata skala nyeri pasien sebelum diberikan Foot massage therapy adalah 5,00 dengan standar deviasi 0,603, nilai terendah 4 dan nilai tertinggi 6. Rata-rata skala nyeri setelah diberikan Foot massage therapy adalah 2,42 dengan standar deviasi 0,515, nilai terendah 2 dan nilai tertinggi 3 .

Penelitian yang dilakukan oleh Luan Tsay (2009) membuktikan bahwa Foot massage therapy bermanfaat dalam penurunan intensitas nyeri akibat luka insisi post operasi abdomen atau laparatomi. Beberapa penelitian lain yang terkait dengan Foot massage therapy, telah menunjukkan manfaat dalam mengatasi berbagai masalah kesehatan terutama mengurangi nyeri yang dapat berpengaruh terhadap psikologis dan kondisi medis. Secara naluri, manusia merespon sakit dan nyeri dengan menggosok-gosok area tersebut. Terapi pijat mengembangkan reaksi ini menjadi cara untuk menghilangkan rasa sakit dan ketegangan (Pustaka Kesehatan Populer, 2009).

Foot Massage dilakukan secara sistematis dengan tekhnik manipulasi manual, seperti menggosok, meremas, atau memutar jaringan lunak (misalnya, otot, ligamen tendon, dan fascia) sehingga meningkatkan jangkauan gerak pasien, mengurangi ambang nyeri, melemaskan otot-otot, dan meningkatkan sirkulasi dan drainase limfati serta memiliki efek biokimia, yaitu meningkatkan kadar dopamin dan limfosit untuk memproduksi sel pembunuh secara alami (Corbin, 2005; Calenda, 2006 dalam Gatlin \& Schulmeister, 2007). Meskipun hanya dilakukan dikaki, tapi foot massage bisa meningkatkan sirkulasi keseluruh tubuh. Pijatan yang lembut pada kaki bisa meningkatkan aliran 
darah ke organ vital, memberikan oksigen dan nutrisi ke berbagai organ serta jaringan tubuh.Jika ada bagian tubuh yang luka, maka foot massage dapat menbantu memperbaiki jaringan yang luka serta membuat tubuh kita menja di lebih rileks dan nyaman.

\section{KESIMPULAN}

Berdasarkan hasil penelitian dapat disimpulkan bahwa rata-rata skala nyeri pasien setelah diberikan Foot massage therapy menurun. Terdapat pengaruh yang signifikan dari Foot massage therapy terhadap penurunan skala nyeri pasien post sectio cesarean. Perawat dapat mengimplementasikan Foot massage therapy sebagai salah satu intervensi keperawatan untuk menurunkan nyeri pasien post sectio cesarean. Penelitian selanjutnya perlu dilakukan dengan sampel yang lebih besar dan dengan variabel yang berbeda.

\section{DAFTAR PUSTAKA}

Anderson \& Cutshall (2007), Nurlalily ((2017). The effect Foot massage on sleep Quality of in ICU. Hal 89-90

Chanif, (2012). Evidance Based Of Pain Management In Post Operative With Foot Massage. Jurnal keperawatan medical bedah. Volume 1. No 2. 91-96. Fakultas keperawatan dan Ilmu kesehatan Universitas Muhammaditah Semarang

Cunningham G.F., Leveno K.J., Bloom S.L., Hauth J.C., Rouse D.J., Spong C.Y., et al.2010. Wiliam Obstetrics. $23^{\text {rd }}$ ed. USA : McGraw-Hill Company

Gatlin. C.G.,\& Schulmeister, L (2007) When Medicine Is Not Enough: Nonpharmacologic Management Of Pain. Clinical Jurnal Of Oncology Nursing

Indriati E. Antropometri untuk keperawatan, kedokteran dan gizi, Yogyakarta: PT. Citra Aji Parama: 2009.

Luan Tsay (2009), dalam K Nila 2016. Pengaruh Foot massage therapy Terhadap Penurunan Skala Nyeri Pasien Post Op Laparatomi RSUP DR. M. Djamil Padang.

Patasik C.K, Tangka, Rottie J. 2013. Efektivitas Teknik Relakasasi Nafas Dalam dan Guided Imagenery. E-Jurnal Keperawatan Vol.1 No.1

Reeder, dkk. 2011. Keperawatan Maternitas Kesehatan Wanita, bayi dan keluarga. Edisi 8. Jakarta: EGC. 